\title{
Folic acid usage and its associated factors among antenatal attendees in a tertiary health facility: Implications for child health
}

\author{
Otaniyenuwa Eloghosa Obarisiagbon, Esohe Olivia Ogboghodo \\ Department of Community Health, University of Benin Teaching Hospital, Benin City, Edo State; \\ Department of Community Health, University of Benin, Benin City, Edo State, Nigeria
}

\begin{abstract}
Globally, an estimated two billion people are affected by deficiencies of essential vitamins and minerals, notably folic acid, which negatively impacts on health and economic development. Maternal folate deficiency is associated with neural tube defects. Thus, getting enough folic acid is important for the rapid cell growth of the placenta and the developing fetus. The objective of this study is to assess the practice of folic acid and its associated factors among pregnant women in University of Benin Teaching Hospital (UBTH). A descriptive cross-sectional study was carried out among 400 pregnant women attending the antenatal clinic at UBTH, selected using a systematic sampling technique. Data was obtained using a structured interviewer-administered questionnaire and analyzed with IBM SPSS version 21.0 software. The level of significance was set at $\mathrm{P}<0.05$. The mean age of the respondents
\end{abstract}

Correspondence: Dr Otaniyenuwa Eloghosa Obarisiagbon, Department of Community Health, University of Benin Teaching Hospital, Benin City, Edo State, Nigeria.

Tel.: 08033700722

E-mail: otaniyenuwa.obarisiagbon@uniben.edu

Key words: Pregnant women, Folic acid, Neural tube defects.

Acknowledgements: The authors wish to thank the research assistants and participants in this study.

Contributions: The authors contributed equally.

Conflict of interest: The authors declare no potential conflict of interest.

Ethics approval and consent to participate: Ethical clearance was obtained from the Ethics Committee, University of Benin Teaching Hospital (ADM/E 22/A/VII14614). Permission was also sought from the Head of Department, Obstetrics and Gynaecology, UBTH. Written informed consent was obtained from clients at the antenatal clinic willing to participate in the study. Confidentiality was assured.

Received for publication: 29 January 2020.

Revision received: 9 June 2020.

Accepted for publication: 9 June 2020.

This work is licensed under a Creative Commons Attribution NonCommercial 4.0 License (CC BY-NC 4.0).

(C) Copyright: the Author(s),2020

Licensee PAGEPress, Italy

Annals of African Medical Research 2020; 3:102

doi:10.4081/aamr.2020.102 was 28.7 (4.2) years. Majority $348(87.0 \%)$ of the respondents had a good practice score of folic acid usage. The factors associated with the practice of folic acid were age $(\mathrm{P}<0.01)$, socioeconomic status $(\mathrm{P}<0.01)$, and parity, $(\mathrm{P}<0.01)$. The determinants of folic acid intake were spouse's level of education $(\mathrm{P}<0.001)$, and planned pregnancy $(\mathrm{P}<0.001)$. The majority of the respondents had a good practice of folic acid usage, and the determinants of practice were spouse's level of education and planned pregnancy. Health education is encouraged to sustain the good practice of folic acid use to prevent neural tube defects.

\section{Introduction}

Globally, an estimated two billion people are affected by a deficiency of essential vitamins such as folic acid. This condition negatively impacts on health and economic development. ${ }^{1}$ The need for folic acid increases especially during periods of rapid cell growth and development. One of such critical periods is pregnancy. ${ }^{2}$ Deficiency of folic acid during pregnancy is associated with several neonatal abnormalities, most especially Neural Tube Defects (NTDs). Worldwide, the prevalence of NTDs is approximately 1.5 per 1000 live births, and the risk of its occurrence is 2 $3 \%$. The prevalence of neural tube defect is $2.75-7$ per 1000 births in Nigeria. ${ }^{3}$ Despite this, the utilization of folic acid by pregnant women is not optimal. Evidence from research, have shown that women attending various antenatal clinics do not take folic acid as recommended and this leads to poor outcomes for both the mother and the neonate. ${ }^{1,4,5}$

Overall, the goal of folic acid utilization in pregnancy is to increase red blood cell folate concentrations to more than 905 $\mathrm{nmol} / \mathrm{L}$, a level associated with a low risk of having a child with an NTD. In women, a 400-ug daily dose of folic acid raises the red blood cell concentration to $1053 \mathrm{nmol} / \mathrm{L}$ from a baseline of 615 $\mathrm{nmol} / \mathrm{L}$ after 12 weeks. Also a once-a-week folic acid supplement (2800ug) raises red blood cell folate concentrations, but not as effectively as daily supplement. ${ }^{6}$

A study carried out on compliance with Iron-Folic Acid (IFA) therapy among190 pregnant women seeking antenatal care in Mangalore City South India revealed that the overall compliance with IFA intake among the subjects was $64.7 \%$. Cost of the tablets had the highest contribution towards compliance, as compliance was higher in instances where the medications were free. Compliance also increased with increase in age of the respondents as well as the number of previous pregnancies. It was also higher among subjects from lower socioeconomic class. These were found to be statistically significant. ${ }^{7}$

A study carried out in 2012 in Uganda on the role of folic acid intake during pregnancy in the prevention of spinal bifida among women attending Antenatal Care (ANC), revealed that 50.5\% of the women took folic acid. None of the women took the vitamin before pregnancy; only $8.1 \%$ took it during the first trimester of 
pregnancy while $42.4 \%$ took it in late pregnancy. ${ }^{8}$

An Ethiopian study in 2014 revealed that $48.4 \%$ of the women took a folic acid supplement at different periods during pregnancy, but, only $1.9 \%$ of women took the supplement at a protective period against neural tube defects. Age, the early timing of antenatal registration, consultation for preconception, previous unsuccessful pregnancies and level of folic acid awareness were significantly associated with folic acid usage for prevention of neural tube defects. ${ }^{6}$

Folic acid awareness and its usage for the prevention of neural tube defects among pregnant women was also assessed in Jos, Nigeria. Findings showed that out of 543 pregnant women surveyed, only $7.4 \%$ consistently took the vitamin during the protective peri-conceptional period. Only $40 \%$ of women with a baby with NTD, took folic acid before pregnancy to prevent a recurrence of the disorder. ${ }^{5}$

In Ibadan Nigeria, a study assessed the knowledge and uptake of folic acid among 300 pregnant women attending antenatal clinics in a secondary health facility. Almost all the women 295 $(98.3 \%)$ reported using folic acid in their current pregnancy with $160(54.2 \%)$ of them reported using it as prescribed. Only $9(3 \%)$ started to use folic acid before the current pregnancy. Employment status of the women was significantly associated with the uptake of folic acid. ${ }^{2}$

Folic acid intake during preconception as well as by pregnant women attending antenatal care is of immense value with substantial health implication for the wellbeing of every child. This practice is in pursuant of its evident role in the prevention of neural tube defects. Prior studies have identified factors associated with antenatal women's compliance to its intake, and these variously included ethnic group, socioeconomic status, age, educational status and planning of pregnancy. 2,6,7,9

Unlike in the preconception period, pregnant women attending antenatal clinics are likely to have access to folic acid tablets, thus the need to assess their practice of folic acid use. Findings from this study will add to the existing body of knowledge on the topic and aid in the organization of advocacy programs to promote the use of folic acid by pregnant women. This study ascertained the usage of folic acid and its associated factors among pregnant women attending antenatal clinic in a tertiary health facility in Benin City, Edo State, to reduce the risk of fetal neural tube defects.

\section{Materials and Methods}

This descriptive cross-sectional study was carried out among pregnant women attending the Antenatal Care Clinic at the University of Benin Teaching Hospital (UBTH), Benin City, a tertiary healthcare facility in Edo State. The University of Benin Teaching Hospital is a tertiary institution founded in $1973 .{ }^{10}$ It is located on the Benin-Lagos expressway. Its boundaries are the University of Benin, the Federal Government Girls' College road, and the Benin-Lagos express road. ${ }^{10}$ In addition to providing healthcare services, the institution provides necessary facilities for training high and middle-level health practitioners, offers research opportunities for staff and interested persons. ${ }^{11}$ It comprises of many departments among which is the Obstetrics and Gynaecology department, where respondents for this study were gotten. The Obstetrics and Gynaecology department contain 124 hospital beds and has a nurse staff strength of $199 .{ }^{12}$

This study was carried out from January to May 2018. Women undergoing treatment for anaemia in pregnancy were excluded from the study. The minimum sample size of 368 was calculated using the Cochrane formula for simple proportion ${ }^{13}$ using $40.0 \%$ as prevalence with a personal history of a baby with NTD from a previous study carried out in Jos, Nigeria. ${ }^{5}$ However, 400 pregnant women participated in this study.

Systematic sampling technique was used to select respondents for this study. The nurses' register served as the sampling frame. The antenatal clinic is run four times a week and the total number of patients who visit per month averages 1520. The number of patients visiting per day was 95. Sampling fraction / sample size/total number of clinic attendees $=0.28$. Number of respondents selected per day $=$ sampling fraction $\times$ number of antenatal attendees per antenatal clinic day $=0.28 \times 95=26.6 \approx 27$. Hence, 27 questionnaires were administered per antenatal clinic day. The sampling interval was calculated as $95 \div 27=3.52 \approx 4$. Every $4^{\text {th }}$ patient on the list for the day was selected until 27 respondents were obtained. This selection was done on every antenatal clinic day until the sample size was attained.

Data was obtained using a pre-tested structured intervieweradministered questionnaire, which comprised of open and closeended questions. The questionnaire was divided into two sections. Section A sought to find the sociodemographic characteristics of the respondents. In contrast, Section B ascertained the practice of folic acid intake as well as associated factors among participants.

A pre-test of the questionnaire was conducted among 40 antenatal attendees at Irrua Specialist Teaching Hospital, Irrua, Edo State. Pre-testing was done to enhance clarity, validity and reliability of the questionnaires and errors noted were corrected before the commencement of the study.

\section{Data analysis}

The questionnaires were collated, screened for completeness and numbered serially. Data was entered into and analyzed using IBM Statistical Package for Scientific Solution (SPSS) version 21 spreadsheet.

Occupation of patients was classified into skill levels according to a modified ILO classification: ${ }^{14}$ i) Skill level 0: Unemployed persons and students; ii) Skill level 1: Office Cleaners, Gardeners, Labourers, Kitchen Assistants; iii) Skill Level 2: Bus Drivers, Secretary, Butchers, Tailors, Sale Assistants, Police Officers, Hairdresser, Mechanics, Electricians; iv) Skill Level 3: Shop Managers, Medical Radiographers, Legal Secretaries, Medical Lab Technicians; v) Skill Level 4: Medical Practitioners, Civil Engineers, Secondary School Teachers, Musicians and Marketing Managers.

\section{Scoring systems \\ Scoring method for socioeconomic status}

Socioeconomic index score was obtained from the addition of the educational score, occupational skill level score and household income. ${ }^{15}$

\section{Scoring method for the practice of folic acid intake}

A total of six questions were used to assess the practice of folic acid intake among the participants. Correct practice was assessed follows; a prescription folic acid in the current pregnancy, regular intake of folic acid, compliance to the timing of intake as prescribed, adherence to dosage, the onset of intake before pregnancy or during the first trimester of pregnancy, and having a history of folic acid intake in previous pregnancies. A score of 1 was given for each correct answer and 0 for each wrong answer, giving a maximum possible score of 6 and a minimum score of 0 . Absolute scores were converted to percentages. Scores $<50 \%$ were adjudged 
as a poor practice of folic acid intake, and scores $\geq 50$ were adjudged as good practice of folic acid intake.

The distribution of the variables was done using univariate analysis. Bivariate analysis was done using Chi-square and Fisher's exact tests. The level of statistical significance was set at $\mathrm{P}<0.05$. Results were presented in prose, frequency tables, and bar charts.

Ethical clearance was obtained from the Ethics Committee, University of Benin Teaching Hospital (ADM/E 22/A/VII14614). Permission was also sought from the Head of Department, Obstetrics and Gynaecology, UBTH. Written informed consent was obtained from clients at the antenatal clinic willing to participate in the study. Confidentiality was assured.

\section{Results}

Table 1 shows the sociodemographic characteristics of respondents and their spouses. A total of 400 respondents with mean age $28.7 \pm 4.2$ years participated in this study. A higher proportion of the respondents, $153(38.2 \%)$ and $136(34.0 \%)$ respondents, were within the age group 25-29 and 30-34 years, respectively. Three hundred and eighty-six (96.5\%) were from monogamous families, and 388 (97\%) were Christians. The majority, 345 (86.1\%) had spouses with a tertiary level of education, while a few $25(6.3 \%)$, $21(5.3 \%)$ and $9(2.3 \%)$ had spouses with a secondary, primary and no formal education respectively. Two thirds, 243 (60.8\%), had a spouse in skill level 4.

Table 2 shows the socioeconomic status of respondents. The majority, $319(79.7 \%)$ respondents, had a tertiary level of education, while $11(2.8 \%)$ had a primary level of education. One hundred and eighty-seven (46.8\%) and 137 (34.3\%) respondents had skill level 4 and skill level 2, respectively. In comparison, 31 $(7.8 \%)$ and $36(6.5 \%)$ had skill level 1 and skill level 3, respectively, and 19 (4.6\%) respondents were unemployed or were students. Three hundred and thirty-nine $(84.7 \%)$ respondents had a household income of $>100,000$ while $26(6.5 \%)$ and $32(8.0 \%)$ had a household income of 50,000-100,000 and $<50,000$ respectively. Three $(0.8 \%)$ respondents did not disclose their household income. Overall, 196 (49.4\%) respondents belonged to high socioeconomic class, $166(41.8 \%)$ belonged to middle socioeconomic class, and $35(8.8 \%)$ belonged to low socioeconomic class.

Table 3 shows the obstetric history of respondents. The majority, $300(75.0 \%)$ respondents, have had 2-4 previous pregnancies. In comparison, $94(23.5 \%)$ have had just one pregnancy in the past, and $6(1.5 \%)$ have had five or more pregnancies. Three hundred $(75.0 \%)$ respondents were currently carrying their second to fourth pregnancy, $94(23.5 \%)$ were currently carrying their first pregnancy, while $6(1.5 \%)$ respondents were currently carrying their fifth pregnancy.

Two hundred and ninety-two (73.0\%) respondents have had 14 children in the past, $105(26.2 \%)$ have not had a child before, while $3(0.8 \%)$ have had five or more children.

Two hundred and seventy $(67.5 \%)$ respondents planned their current pregnancy, while 130 (32.5\%) did not plan their current pregnancy.

Three hundred and ninety-two $(98.0 \%)$ respondents had never given birth to a child with neural tube defects. In comparison, 8 $(2.0 \%)$ respondents had a history of a child with neural tube defects.

Three hundred and ninety-eight (99.5\%) respondents did not know any woman who had a baby with neural tube defects. In comparison, $2(0.5 \%)$ knew a woman who had a baby with neural tube defects.

Table 4 presents the practice of folic acid intake and associated factors among respondents. The majority, 366 (91.5\%) had folic acid prescribed in their current pregnancy. Of those that had folic acid prescribed in their current pregnancy, 352 (96.2\%) took the vitamin while $14(3.8 \%)$ did not take it. Three hundred and fourteen $(89.2 \%)$ took it as prescribed, $30(8.5 \%)$ took it as soon as they remembered while $8(2.3 \%)$ took it once in a while.

Three hundred and forty-four $(98.0 \%)$ of the respondents that took folic acid has never had any side effects from its usage. In

Table 1. Sociodemographic characteristics of respondents and their spouses.

\begin{tabular}{lcc}
\hline Variable & Frequency $(\mathbf{N}=400)$ & Percent \\
Age group (years) & & \\
$15-19$ & 3 & 0.8 \\
$20-24$ & 68 & 17.0 \\
$25-29$ & 153 & 38.2 \\
$30-34$ & 136 & 34.0 \\
$>35$ years & 40 & 10.0 \\
Mean age (SD) & $28.7( \pm 4.2)$ & \\
\hline Family type & & \\
Monogamy & 386 & 96.5 \\
Polygamy & 14 & 3.5 \\
Religion & & \\
Christian & 388 & 97.0 \\
Muslim & 12 & 3.0 \\
\hline Spouse level of education & & \\
No formal education & 9 & 2.3 \\
Primary & 21 & 5.3 \\
Secondary & 25 & 6.3 \\
Tertiary & 345 & 86.1 \\
Spouse skill level & & \\
Unemployed, students & & \\
Skill level 1 & 17 & 4.2 \\
Skill level 2 & 120 & 30.0 \\
Skill level 3 & 20 & 5.0 \\
Skill level 4 & 243 & 60.8 \\
\hline
\end{tabular}

Table 2. Socioeconomic status of respondents.

\begin{tabular}{lcc}
\hline Variable & Frequency $(\mathrm{N}=400)$ & Percent \\
Level of education & & \\
$\quad$ No formal education & 12 & 3.0 \\
Primary & 11 & 2.8 \\
Secondary & 58 & 14.5 \\
$\quad$ Tertiary & 319 & 79.7 \\
Skill level & & \\
$\quad$ Unemployed, students & 19 & 4.6 \\
Skill level 1 & 31 & 7.8 \\
Skill level 2 & 137 & 34.3 \\
Skill level 3 & 36 & 6.5 \\
$\quad$ Skill level 4 & 187 & 46.8 \\
\hline Household income & & \\
$\quad<50,000$ & 32 & 8.0 \\
50,000-100,000 & 26 & 6.5 \\
$\quad$ 100,000 & 339 & 84.7 \\
$\quad$ Not disclosed & 3 & 0.8 \\
Socioeconomic status (n=397) & & \\
Low socioeconomic class & 35 & 8.8 \\
Middle socioeconomic class & 166 & 41.8 \\
High socioeconomic class & 196 & 49.4 \\
\hline
\end{tabular}


comparison, $8(2.0 \%)$ has had side effects following folic acid usage. Of the respondents that have had side effects following folic acid usage, 7 (87.5\%) experienced nausea following intake, while $1(12.5 \%)$ experienced abdominal cramps following intake.

Three hundred and sixteen $(90.0 \%)$ respondents that took folic acid also took it in their previous pregnancy. In comparison, 36 $(10.0 \%)$ did not take it in their previous pregnancy.

Overall, $348(87.0 \%)$ respondents had a good practice of folic acid usage in pregnancy, while $52(13.0 \%)$ had a poor practice of folic acid usage in pregnancy.

Concerning factors associated with the practice of folic acid intake, (Table 5) age $(\mathrm{P}=<0.001)$, family type $(\mathrm{P}=0.001)$, spouses level of education $(\mathrm{P}<0.001)$, spouse skill level $(\mathrm{P}<0.01)$ and socioeconomic status $(\mathrm{P}<0.01)$ were identified as significant factors.

Table 6 shows the association between obstetric history and practice of folic acid intake among respondents. An increasing number of pregnancies, $(\mathrm{P}=0.021)$, the order of index pregnancy, $(\mathrm{P}<0.001)$, number of children $(\mathrm{P}<0.001)$ and planned pregnancy $(\mathrm{P}<0.001)$ were identified as significant obstetric factors associated with the practice of folic acid intake among respondents. Table 7 shows the Logistic regression model for determinants of practice of folic acid intake among respondents. The variables in the model accounted for between $20.3 \%-37.7 \%$ of the variation observed in the outcome variable (level of good practice).

Respondents whose husbands had a secondary level of education and above were $6.970(95 \% \mathrm{Cl}=2.229-21.791)$ times likely, to have good practice than respondents whose husbands had a primary level of education and below. This finding was statistically significant $(\mathrm{P}=0.001)$.

Respondents who planned their pregnancy were 3.866 (95\% $\mathrm{Cl}=1.844-8.103$,) times likely to have good practice than respondents who did not plan their pregnancy; and this was statistically significant $(\mathrm{P}<0.001)$.

Table 3. Obstetric history of respondents.

\begin{tabular}{lcc} 
Variable & Frequency $(\mathrm{N}=400)$ & Percent \\
Number of previous pregnancies & & \\
$\quad$ 1 & 94 & 23.5 \\
$2-4$ & 300 & 75.0 \\
5 and above & 6 & 1.5 \\
Order of index pregnancy & 94 & \\
$\quad$ First & 300 & 23.5 \\
$\quad$ Second to fourth & 6 & 75.0 \\
\hline Fifth and above & & 1.5 \\
$\quad$ Number of children & 105 & \\
$\quad 0$ & 295 & 26.2 \\
$\quad$ 1-5 & & 73.8 \\
Planned pregnancy & 270 & 67.5 \\
$\quad$ Yes & 130 & 32.5 \\
$\quad$ No & & \\
Had a baby with neural tube defects & 8 & 2.0 \\
$\quad$ Yes & 392 & 98.0 \\
$\quad$ No & & \\
Know someone who had a baby & & 0.5 \\
with neural tube defects & 2 & 99.5 \\
$\quad$ Yes & 398 & \\
No
\end{tabular}

\section{Discussion}

One-third of the respondents were aged 25-29 (28.7 \pm 4.2$)$ years. This mean age is within the age bracket for women of reproductive years (15-49 years). The finding is similar to findings from a study carried out in the United Arab Emirates, where about onethird of the women were aged 25-29 years. ${ }^{16}$ However, it differs from findings from the studies conducted in 2013 in Northern Uganda where the mean age of the respondents was 29 years $^{8}$ and in 2013 in Jos Nigeria where the mean age of the women was 29.9 \pm 4.7 years. $^{5}$

Age was a significant factor in folic acid use in this study. The age range of 25-29 years reflects women who are actively procreating, thus more exposed, from experiences, on the benefits taking folic acid. This finding is important because the good practice of folic acid intake amongst higher proportion childbearing women will translate to having more children born without the burden of neural tube defects.

About half of the respondents had a high socioeconomic status, in comparison to middle and low socioeconomic statuses. Women with high socioeconomic statuses are likely to have the financial power in addition to knowledge, thus adopting better health-seeking behaviours and seeking safer pregnancies and healthier children. This finding is similar to findings from the study done in 2012 in Ibadan Nigeria. ${ }^{17}$

As regards the practice of folic acid intake among the respondents, the majority had an overall good practice of folic acid intake. The finding is similar to findings from the studies done in 2017 in South Africa, ${ }^{18}$ and Jos, ${ }^{5}$ and Ibadan, ${ }^{17}$ Nigeria. This finding is not far-fetched from expectations for a populace in an urban setting with easy access to both secondary and tertiary health facilities well equipped for the provision of maternal and child health services. This finding may be due to the predominance tertiary level of education among the respondents as well as their high socioeconomic status. Good practice of folic acid intake will be advantageous for the health of every child preventing the incidence of neural tube defects. A little above one-tenth of the respondents had a poor practice of folic acid intake, and this is very significant. Hence, measures aimed at continued advocacy of the importance of the vitamin should be intensified by relevant authorities to encourage the good practice of folic acid intake in every peri-con-

Table 4. Practice of folic acid intake and associated factors among respondents.

\begin{tabular}{lcc} 
Variable & Frequency $(\mathrm{N}=400)$ & Percent \\
Take folic acid in current pregnancy $(\mathrm{n}=366)$ & & \\
$\quad$ Yes & 352 & 96.2 \\
$\quad$ No & 14 & 3.8 \\
Ever had side effects following folic acid $(\mathrm{n}=52)$ & & \\
$\quad$ Yes & 8 & 2.0 \\
$\quad$ No & 344 & 98.0 \\
\hline Side effects following folic acid intake ( $\mathrm{n}=8)$ & & \\
$\quad$ Nausea & 7 & 87.5 \\
$\quad$ Abdominal cramp & 1 & 12.5 \\
History of folic acid intake in the previous & & \\
pregnancy (n=352) & 316 & \\
$\quad$ Yes & 36 & 90.0 \\
$\quad$ No & & 10.0 \\
\hline Overall practice score & 348 & \\
$\quad$ Good practice & 52 & 13.0 \\
$\quad$ Poor practice &
\end{tabular}


Table 5. Association between sociodemographic characteristics and practice of folic acid intake among respondents.

\begin{tabular}{|c|c|c|c|c|}
\hline Variable & $\begin{array}{c}\text { Pood }(n=348) \\
\text { Freq }(\%)\end{array}$ & $\begin{array}{c}\text { Poor }(\mathrm{n}=52) \\
\text { Freq }(\%)\end{array}$ & Test statistics & P-value \\
\hline $\begin{array}{l}\text { Age group (years) } \\
15-19 \\
20-24 \\
25-29 \\
30-34 \\
>35\end{array}$ & $\begin{array}{c}1(33.3) \\
60(88.2) \\
143(93.5) \\
113(83.1) \\
31(77.5)\end{array}$ & $\begin{array}{c}2(66.7) \\
8(11.8) \\
10(6.5) \\
23(16.9) \\
9(22.5)\end{array}$ & Fisher's = 16.743 & $0.001^{*}$ \\
\hline $\begin{array}{l}\text { Family type } \\
\text { Monogamy } \\
\text { Polygamy } \\
\end{array}$ & $\begin{array}{c}340(88.1) \\
8(57.1)\end{array}$ & $\begin{array}{c}46(11.9) \\
6(42.9)\end{array}$ & $X^{2}=11.435$ & $0.001^{*}$ \\
\hline $\begin{array}{l}\text { Spouse level of education } \\
\text { No formal education } \\
\text { Primary } \\
\text { Secondary } \\
\text { Tertiary }\end{array}$ & $\begin{array}{c}6(66.7) \\
6(28.6) \\
19(76.0) \\
317(91.9)\end{array}$ & $\begin{array}{l}4(33.3) \\
15(71.4) \\
6(24.0) \\
28(8.1)\end{array}$ & Fisher's = 52.128 & $<0.001^{*}$ \\
\hline $\begin{array}{l}\text { Spouse skill level } \\
\text { Skill level } 1 \\
\text { Skill level } 2 \\
\text { Skill level } 3 \\
\text { Skill level } 4 \\
\end{array}$ & $\begin{array}{c}8(47.1) \\
101(84.2) \\
17(85.0) \\
222(91.4)\end{array}$ & $\begin{array}{l}9(52.9) \\
19(15.8) \\
3(15.0) \\
21(8.6)\end{array}$ & Fisher's $=21.683$ & $<0.001^{*}$ \\
\hline $\begin{array}{l}\text { Socioeconomic status } \\
\text { Low socioeconomic status } \\
\text { Middle socioeconomic status } \\
\text { High socioeconomic status }\end{array}$ & $\begin{array}{l}21(60.0) \\
138(83.1) \\
186(94.9) \\
\end{array}$ & $\begin{array}{c}14(40.0) \\
28(16.9) \\
10(5.1) \\
\end{array}$ & $X^{2}=35.335$ & $<0.001 *$ \\
\hline
\end{tabular}

*Statistically significant.

Table 6. Association between obstetric history and practice of folic acid intake among respondents.

\begin{tabular}{|c|c|c|c|c|}
\hline Variable & $\begin{array}{c}\text { P } \\
\text { Good }(n=348) \\
\text { Freq }(\%)\end{array}$ & $\begin{array}{c}\text { Poor }(n=52) \\
\text { Freq }(\%)\end{array}$ & Test statistics & P-value \\
\hline $\begin{array}{l}\text { Number of previous pregnar } \\
\text { One } \\
\text { Two } \\
\text { Three } \\
\text { Four } \\
\text { Five and above }\end{array}$ & $\begin{array}{l}88(93.6) \\
131(85.1) \\
93(86.9) \\
33(84.6) \\
3(50.0)\end{array}$ & $\begin{array}{c}6(6.4) \\
23(14.9) \\
14(13.1) \\
6(15.4) \\
3(50.0)\end{array}$ & Fisher's = 10.375 & $0.021^{*}$ \\
\hline $\begin{array}{l}\text { Order of index pregnancy } \\
\text { First } \\
\text { Second } \\
\text { Third } \\
\text { Fourth } \\
\text { Fifth and above }\end{array}$ & $\begin{array}{c}88(93.6) \\
128(92.8) \\
96(81.4) \\
33(75.0) \\
3(50.0)\end{array}$ & $\begin{array}{c}6(6.4) \\
10(7.2) \\
22(18.6) \\
11(25.0) \\
3(50.0)\end{array}$ & Fisher's = 21.990 & $<0.001^{*}$ \\
\hline $\begin{array}{l}\text { Number of children } \\
\quad 0-3 \\
>3\end{array}$ & $\begin{array}{c}315(89.5) \\
33(68.8)\end{array}$ & $\begin{array}{l}37(10.5) \\
15(31.3)\end{array}$ & $X^{2}=16.023$ & $<0.001^{*}$ \\
\hline $\begin{array}{l}\text { Planned current pregnancy } \\
\text { Yes } \\
\text { No }\end{array}$ & $\begin{array}{c}253(93.7) \\
95(73.1)\end{array}$ & $\begin{array}{c}17(6.3) \\
35(26.9)\end{array}$ & $X^{2}=33.010$ & $<0.001^{*}$ \\
\hline
\end{tabular}

*Statistically significant.

Table 7. Logistics regression model for determinants of practice of folic acid intake among respondents.

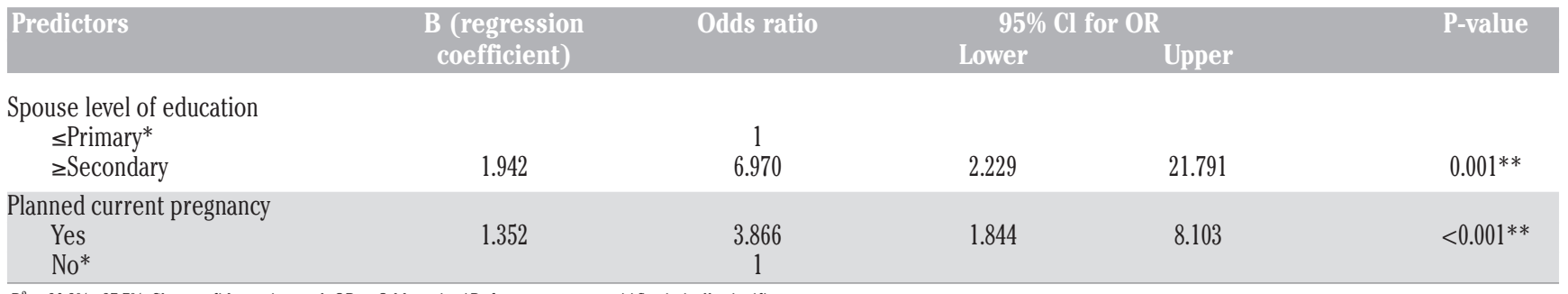

$\mathrm{R}^{2}=20.3 \%-37.7 \%, \mathrm{Cl}=$ confidence interval, OR $=$ Odds ratio. ${ }^{*}$ Reference category. ${ }^{*}$ Statistically significant. 
ceptional woman.

In this study, planned pregnancy was found to be a determinant of folic acid use. This finding is similar to results obtained by researchers in Portugal, Ireland and Canada, respectively. They independently assessed the determinants of folic acid use in pregnancy and found that planned pregnancy was an important predictor of folic acid use. ${ }^{19-21}$ Women who plan their pregnancies are more likely to seek prenatal care and commence folic acid supplementation and have better pregnancy outcomes. ${ }^{22-23}$ Pregnancy planning is an ideal time to adopt behaviours that could improve the health of both mother and foetus. Planned pregnancy also allows efficient use of meagre resources in reducing infant and child mortality through quality health care, including immunization services, access to adequate nutrition, water and sanitation facilities. These child survival strategies increase the life expectancy in children.

Also, higher spousal level of education was a predictor of folic acid use among participants. This similarity was observed in China. ${ }^{24}$ On the contrary, it was observed that the husband's educational status reduced the odds of good folic acid supplementation among pregnant women in Ethopia. ${ }^{25,26}$ This observation underscores the importance of male involvement in pregnancy. Education increases knowledge and uptake of folic acid supplementation, and informed spouses can boost supplementation by providing reminders and other support to help with pill taking. Partners are encouraged to assist in promoting compliance with folic acid supplementation in pregnant women.

\section{Limitations of the study/opportunities for further research}

There was the possibility of information bias because of conservativeness amongst some respondents, which made them unwilling to answer questions or discuss issues relating to reproductive health. This bias was reduced by reassuring the respondents of the confidentiality of the information obtained. However, this calls for qualitative studies on the subject to further explore the topic and provide direct correspondence of respondents' opinions.

This study focused on pregnant women attending antenatal clinics. However, the importance of folic acid in the prevention of neural tube defects stretch beyond the period of pregnancy to the preconception period among all women of reproductive age group. Hence community-based studies are required on the importance of folic acid intake among this population of women.

\section{Conclusions}

The majority of the respondents had a good practice of folic acid usage. The factors found to be significantly associated with the practice of folic acid intake included: age, family type, socioeconomic status, spouse's level of education and skill level, number of previous pregnancies, and planned pregnancy.

There should be regular health education of women attending antenatal care on the importance of folic acid supplementation in pregnancy as this will reinforce good practice. Planned pregnancies should be encouraged to sustain the good practice of folic acid supplementation.

\section{References}

1. Yang T, Gu Y, Wei X, et al. Periconceptional folic acid supple- mentation and vitamin B12 status in a cohort of Chinese early pregnancy women with the risk of adverse pregnancy outcomes. J Clin Biochem Nutr 2017;60:136-42.

2. Omowumi A, Ndikom C, Magbagbeola D. Knowledge and uptake of folic acid among pregnant women attending a secondary health facility in Ibadan. Br J Midwifery 2017;25:2-8.

3. Anyanwu LC, Danborno B, Hamman WO. The prevalence of neural tube defects in live born neonates in Kano, NorthWestern Nigeria. Afr J Med Sci 2015;2:105-9.

4. Köken GN, Derbent AU, Erol O, et al. Awareness and use of folic acid among reproductive age and pregnant women. J Turk Ger Gynecol Assoc 2013;14:87-91.

5. Anzaku AS. Assessing folic acid awareness and its usage for the prevention of neural tube defects among pregnant women in Jos, Nigeria. J Basic Clin Reprod Sci 2013;2:13-7.

6. Meselech A, Zeleke E, Shimelash W, Ayanaw B. Folic acid usage and associated factors in the prevention of neural tube defects among pregnant women in Ethiopia: a cross-sectional study. BMC Pregnancy Childbirth 2017; 17:313.

7. Mithra P, Unnikrishnan B, Rekha T, et al. Compliance with iron-folic acid (IFA) therapy among pregnant women in an urban area of south India. Afr Health Sci 2014;14:255-60.

8. Femke B, Rita L, Peter K, et al. Prevention of spina bifida: folic acid intake during pregnancy in Gulu district, northern Uganda. Pan Afr Med J 2015;20:90-9.

9. Min Jin k, Jihyun K, Eun JH, et al. Awareness, knowledge and use of folic acid among non-pregnant Korean women of childbearing age. Nutr Res Pract 2017;12:78-84.

10. University of Benin Teaching Hospital. Available from: https://ubth.business.site/?utm_source=gmb\&utm_medium=re ferral Accessed December 24 $4^{\text {th }}, 2019$.

11. University of Benin Teaching Hospital. Available from: https://en.wikipedia.org/wiki/University_of_Benin_Teaching_ Hospital Accessed December $24^{\text {th }}, 2019$.

12. University of Benin Teaching Hospital (UBTH). About UBTH: General information. 2019. Available at http://www.ubth.org. Accessed December 24 ${ }^{\text {th }}, 2019$.

13. Cochran WG. Sampling techniques $2^{\text {nd }}$ Edition New York, John Wiley and Sons, inc 1963.pdf Available from https://hwbdocuments.env.nm.gov/Los\%20Alamos\%20National\%20Labs /General/14447.pdf. Accessed December 24 $4^{\text {th }}, 2019$.

14. International Labour Organization (ILO). International Standard Classification of Occupations. ILO 2012;1:12-4.

15. Olusanya O. Okpere EE. Ezimokhai M. Scoring system for social class. Med J West Afr 1993;4:205.

16. Al Hossani H, Abouzeid H, Salah MM, et al. Knowledge and practices of pregnant women about folic acid in pregnancy in Abu Dhabi, United Arab Emirates. East Mediterr Health J 2010;16:402-7. Available from: http://www.who.int/iris/handle/10665/117885.Accessed December 25th 2019.

17. Akeem LT, Adeleye AO. Determinants of folic acid intake during preconception and in early pregnancy by mothers in Ibadan, Nigeria. Pan Afr Med J 2014;19:113-9.

18. Xikombiso M, Matodzi C. Compliance with the consumption of iron and folate supplements by pregnant women in mafikeng local municipality, North West province, South Africa. Afr Health Sci 2017;17:657-70.

19. Lunet N, Rodrigues T, Correia S, et al. Adequacy of prenatal care as a major determinant of folic acid, iron, and vitamin intake during pregnancy. Cad Saúde Pública 2008:24;1151-7.

20. Mcdonnell R, Johnson Z, Doyle A, Sayers, G. Determinants of folic acid knowledge and use among antenatal women. J Public Health Med 1999:21;145-9. 
21. Morin P, De Wals P, St-Cyr-Tribble D, et al. Pregnancy planning: a determinant of folic acid supplements use for the primary prevention of neural tube defects. Can J Public Health 2002;93:259-263.

22. Nilsen RM, Leoncini E, Gastaldi P, et al. Prevalence and determinants of preconception folic acid use : an Italian multicenter survey. Ital J Pediatr 2016:42;1-10.

23. Sijpkens MK, van Voorst SF, Rosman AN, et al. Change in lifestyle behaviors after preconception care: a prospective cohort study. Am J Health Promot 2020;1-5.

24. Yan J, Zheng YZ, Cao LJ, et al. Periconceptional folic acid supplementation in chinese women: a cross-sectional study. Biomed Environ Sci 2017;30:737-48.

25. Agegnehu G, Atenafu A, Dagne H, Dagnew B. Adherence to iron and folic acid supplement and its associated factors among antenatal care attendant mothers in lay armachiho health centers, northwest Ethiopia. Int J Reprod Med 2019;2019: 5863737.

26. Tarekegn M, Wubshet M, Atenafu A, et al. Antenatal care and mothers' education improved iron-folic acid adherence at denbiya district health centres, northwest Ethiopia: using pills count method. Arch Public Health 2019;77:1-6. 